BMJ Open Sport \& Exercise Medicine

\title{
Development and validation of the athletes' rights survey
}

\author{
Yetsa A Tuakli-Wosornu (D) , ${ }^{1,2}$ Demetri Goutos (D) ${ }^{3}$ Ioana Ramia, ${ }^{4}$ \\ Natalie R Galea, ${ }^{5}$ Margo Mountjoy, ${ }^{6}$ Katharina Grimm, ${ }^{7}$ Sheree Bekker ${ }^{8}$
}

To cite: Tuakli-Wosornu YA, Goutos D, Ramia I, et al. Development and validation of the athletes' rights survey. BMJ Open Sport \& Exercise Medicine 2021;7:e001186. doi:10.1136/ bmjsem-2021-001186

YAT-W and DG contributed equally.

Accepted 18 0ctober 2021

Check for updates

(C) Author(s) (or their employer(s)) 2021. Re-use permitted under CC BY-NC. No commercial re-use. See rights and permissions. Published by BMJ.

${ }^{1}$ Department of Chronic Disease Epidemiology, Yale University School of Public Health, New Haven, Connecticut, USA

${ }^{2}$ Physical Medicine and Rehabilitation, University of Pittsburgh School of Medicine, Pittsburgh, PA, USA

${ }^{3}$ Sports Equity Lab, New Haven, Connecticut, USA

${ }^{4}$ Centre for Social Impact, University of New South Wales, Sydney, New South Wales, Australia

${ }^{5}$ Australian Human Rights Institute, University of New South Wales, Sydney, New South Wales, Australia

${ }^{6}$ Michael G. DeGroote School of Medicine, McMaster University, Hamilton, Ontario, Canada ${ }^{7}$ Sports Equity Lab,

Johannesburg, South Africa

${ }^{8}$ Department for Health, University of Bath, Bath, UK

Correspondence to Dr Yetsa A Tuakli-Wosornu; yetsa.tuakli-wosornu@yale.edu

\section{ABSTRACT}

A recognised imbalance of power exists between athletes and sporting institutions. Recent cases of systemic athlete abuse demonstrate the relationship between power disparities and harassment and abuse in sport. Embedding human rights principles into sporting institutions is a critical step towards preventing harassment and abuse in sport. In 2017, the World Players Association (WPA) launched the Universal Declaration of Player Rights. A year later, the International Olympic Committee (IOC) developed their Athletes' Rights and Responsibilities Declaration. These two documents codify benchmarks 'for international sporting organisations to meet their obligations to protect, respect and guarantee the fundamental rights of players'. This paper is the first project exploring athletes' knowledge, understanding and awareness of rights in the sports context. This study presents the development and validation of a survey investigating athletes' knowledge of these declarations, associated attitudes/beliefs and understanding of how these rights can be enacted in practice. The survey includes 10 statements of athlete rights based on the WPA and IOC declarations. Face validation was assessed by distributing the survey to 10 athletes and conducting qualitative interviews with a subgroup of four athletes. The survey was reworked into 13 statements, and the tool was validated with 611 responses through confirmatory factor analysis. Key findings include a weak correlation between athletes' knowledge and their attitudes/beliefs, and challenges with the interpretation of words such as 'pressure,' 'violence,' 'harassment' and 'intimidation.' This validation puts forward the first survey instrument to directly test athletes' knowledge, attitudes and beliefs about rights in sport.

\section{INTRODUCTION}

In November 2019, World Athletics abruptly removed selected events from Diamond League competitions without athlete input. In response, American triple jumper Christian Taylor started a social media campaign \#wearethesport. ${ }^{1}$ Global track and field athletes joined Taylor to challenge a seemingly arbitrary reconfiguration of a longstanding Games programme. \#wearethesport required athletes to unify their collective voice for change. The campaign raised questions about who holds rights and can exert power in sport.
Key messages

What is already known?

- All forms of harassment and abuse in sport are a breach of human rights. Integrating human rights with sport is one important step in building sport environments that are free from harassment and abuse.

- The International Olympic Committee and World Players Association have independently developed declarations of athletes' rights in the sports context.

- Despite these declarations, egregious cases of abuse still occur in sport with unsettling regularity, and athletes' rights while they are training and competing remains a contested space. Athletes' unfamiliarity with their human rights may contribute to the existing power imbalance between athletes and sporting institutions, which sets the stage for unethical practices to take place in silence.

What could this study add?

- This validation paper describes the development of the first survey instrument to understand better athletes' knowledge and attitudes and beliefs about their documented rights in sport.

- The study also demonstrates a weak correlation between athletes' knowledge of rights and their attitudes/beliefs about them, as well as inconsistencies with athletes' interpretation of words such as 'pressure,' 'violence,' 'harassment' and 'intimidation.'

These questions, among others, are essential for Safe Sport, that is, sports environments that are free from all forms of harassment and abuse. ${ }^{2}$ If athletes lack confidence in or are unsure of their basic human entitlements, though they are central to sport, they may be functionally censored in it. Recent cases of systemic athlete abuse in summer and winter sports demonstrate a close relationship between athletes being systemically silenced and exploitation: consider the abuse of American gymnasts by their team doctor, of Afghanistan women's football team members by their national federation president and other officials, or of two-time Olympic shorttrack speedskating champion Shim Suk-hee by her coach. ${ }^{3-5}$ All forms of abuse, including psychological, physical or sexual abuse, 
neglect, harassment or discrimination of any kind, are human rights violations. ${ }^{2}$

In 2017, World Players' Association (WPA) asserted, 'The athlete... is at the centre of the intersection between sport and human rights. ${ }^{6}$ Human rights are the inalienable claims to freedom, expression, security, dignity, privacy, remedy and redress inherent to all human beings without distinction of any kind (eg, race, colour, sex, language, religion, political or other opinions, national or social origin, property, birth or another status). ${ }^{7}$ This becomes important when we consider those who are rendered particularly vulnerable to abuse in sport: young, elite, gender non-binary, girl/woman and disabled athletes. ${ }^{89}$ Sports organisations are not exempt from the obligation to meet human rights criteria, and there is a moral and legal duty on sports organisers to ensure the risk of abuse is identified and mitigated. ${ }^{26}$

In 2018, the International Olympic Committee (IOC) Athletes Commission published the Athletes' Rights and Responsibility Declaration. According to the IOC, the declaration is 'inspired by', (but not based on), 'the United Nations' Universal Declaration of Human Rights and other internationally recognised human rights standards, principles and treaties. ${ }^{, 10}$ Furthermore, the declaration lays out a "common set of aspirational rights and responsibilities for athletes within the Olympic Movement and the jurisdiction of its members. ${ }^{10}$ This declaration was developed in consultation with IOC Athletes Commission and shaped by a survey of 4292 elite athletes. ${ }^{10}$ The stated goal of the Declaration is 'to further support athletes-no matter their sport, age, gender, or nationality, by outlining a common set of aspirational rights and responsibilities for athletes within the Olympic Movement'. ${ }^{10}$

Though this, and a similar declaration of players' rights developed by the WPA do not completely align with each other, ${ }^{11}{ }^{12}$ integrating human rights into sports is critical to the practice of safeguarding athletes $(n b$ : the term 'player(s),' used by the World Players Association, describes athletes who participate in team sports; we use the term 'athlete(s)' throughout the manuscript to describe athletes who participate in both individual and team sports). ${ }^{13-15}$ Nevertheless, to our knowledge, there has been no investigation into adult athletes' understandings of their human rights within sport wherever and however it is played (region, sport and performance level). Most sport safeguarding studies have heretofore overlooked knowledge and understanding of human rights-including access to remedy and redress-as the central lens to investigating safeguarding strategies. This is a concerning knowledge gap because individuals are better equipped to know that they should be defended when they have a concrete belief in their rights, and trust their environment to uphold them (figure 1).

To prevent athlete abuse, sport must ultimately undergo a culture change where well-being is prioritised rather than winning. ${ }^{16}{ }^{17}$ One component of this shift is athletes at appropriate ages and developmental stages being empowered to self-identify as rights-bearers in sport. Yet, human rights in the sporting context are still contested, as recent debates about the IOC's Rule 50 show us. Until more is known about the local contexts and ways of thinking in which athletes negotiate personal agency while training and competing, we cannot assume that published rights declarations will improve athletes' sport experiences, that the formal and legal understanding of human rights is protected, nor that it has universal applicability to all sport settings.

This study aimed to develop and validate a reliable measurement tool for assessing athletes' knowledge, attitudes and beliefs about their rights in sport, as articulated by the WPA and IOC Declarations.

\section{METHODS}

A three-step mixed-methods approach was used $^{18}{ }^{19}$ : a literature review, ${ }^{1}$ item development and face validation, ${ }^{2}$ structural validation and internal consistency testing (figure 2).

\section{Patient and public involvement statement}

To ensure the survey was easy to understand and valid, the final version relied on the input of athletes, described in step 2: Item development and face validation. Research findings will be disseminated to all participants in the form of a plain-language summary.

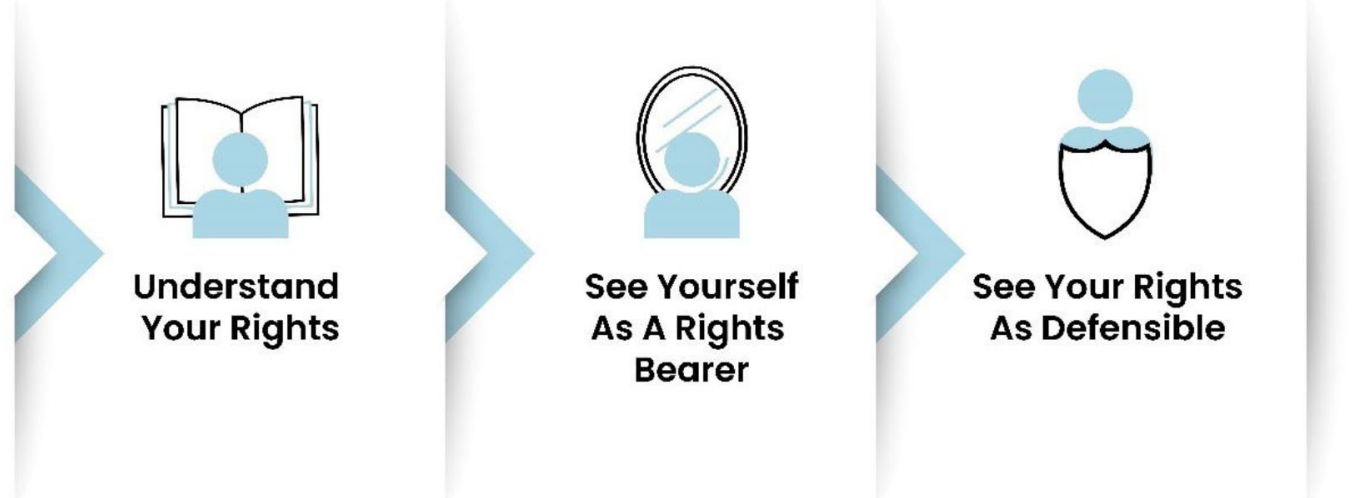

Figure 1 Path to seeing rights as defensible. 


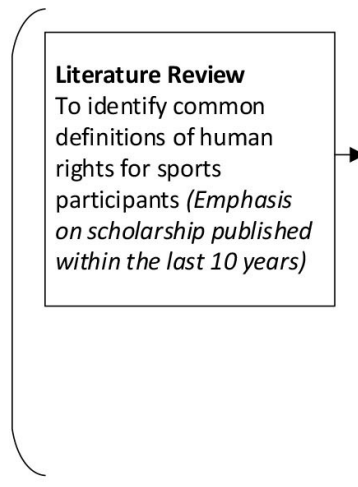

Identification of Rights

- 24 rights-related statements from two rights declarations were organized by concept found in review

- Rights narrowed down to those that represented concepts most

likely to apply to athletes and players in most sport sub-contexts

- Direct language used from most applicable rights declaration

Step 1. Rapid Literature

Review and Item Drafting
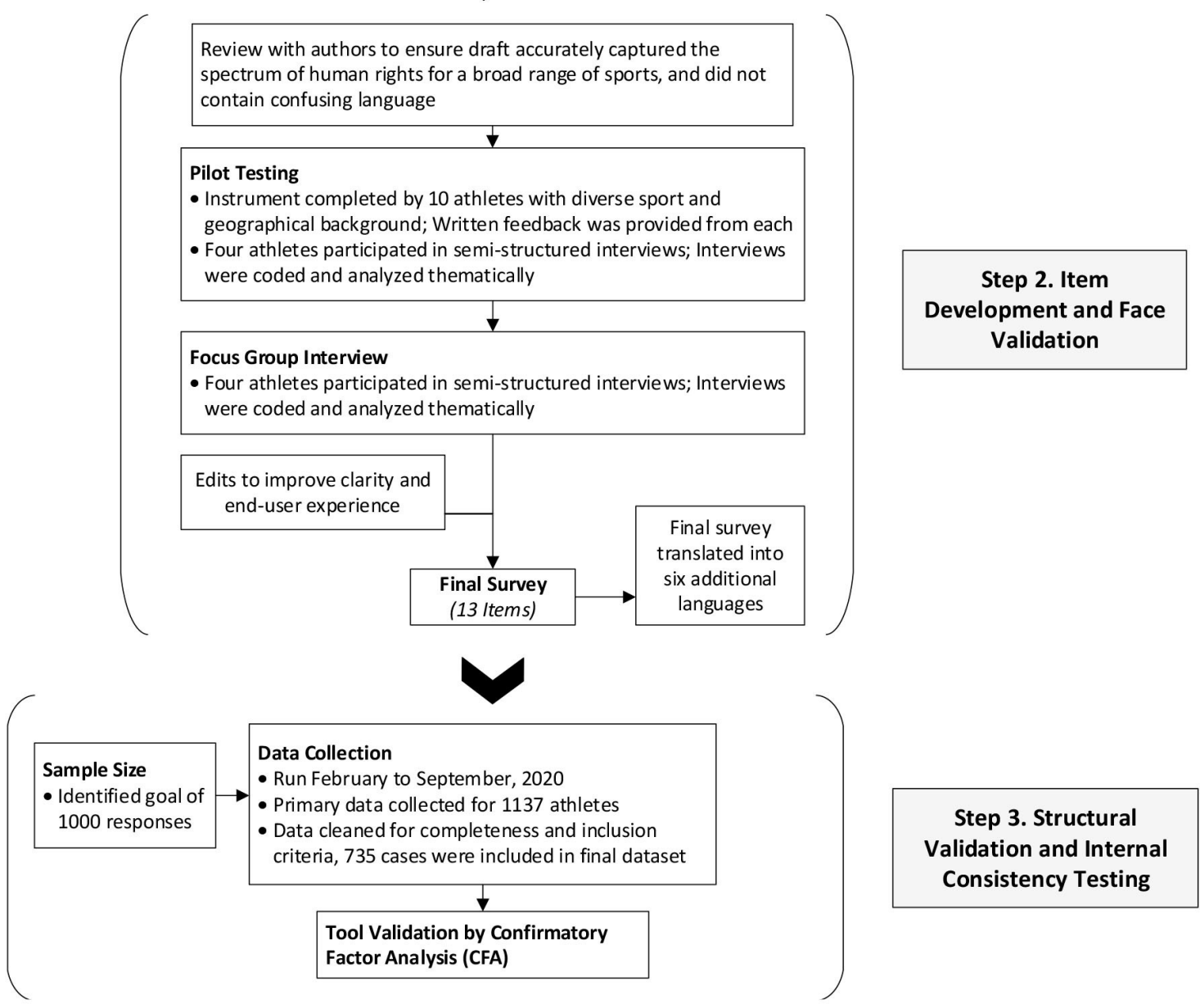

Attitudes/Beliefs

- Rights statements adapted asking athlete to respond to hypothetical scenarios using a 7-point Likert scale

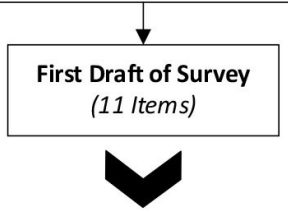

Review with authors to ensure draft accurately captured the contain confusing language

Pilot Testing

- Instrument completed by 10 athletes with diverse sport and eographical background; Written feedback was provided from each

- Four athletes participated in semi-structured interviews; Interviews

its to improve clarity and end-user experience

Run February to September, 2020

Data cleaned for completeness and inclusion 735 cases were included in final dataset

ool Validation by Confirmatory

Analysis (CFA)

Figure 2 Flow chart of athletes' rights survey validation.

\section{Step 1: rapid literature review and item drafting}

A literature search was conducted in PubMed, Scopus, Web of Science, as well as grey literature using keywords such as athlete(s), child/children, sport(s), athletics, high-performance(s) and human right(s), with emphasis on scholarship published within the last decade. The intent was to identify common conceptions of human rights for athletes in sports. A search identified no relevant measurement tools, and only two published human rights declarations focused on the rights of athletes in sport contexts: The WPA Universal Declaration of Player Rights and the IOC Athletes' Rights and Responsibilities Declaration. ${ }^{10} 20$ These publicly available declarations contain 17 and 12 rights-related statements, respectively, many of which overlap.

The authors, an interdisciplinary team from sports science, human rights, and public health, organised the 29 distinct rights statements thematically by concept, then narrowed them to only those representing concepts that apply across most sport contexts (considering factors 


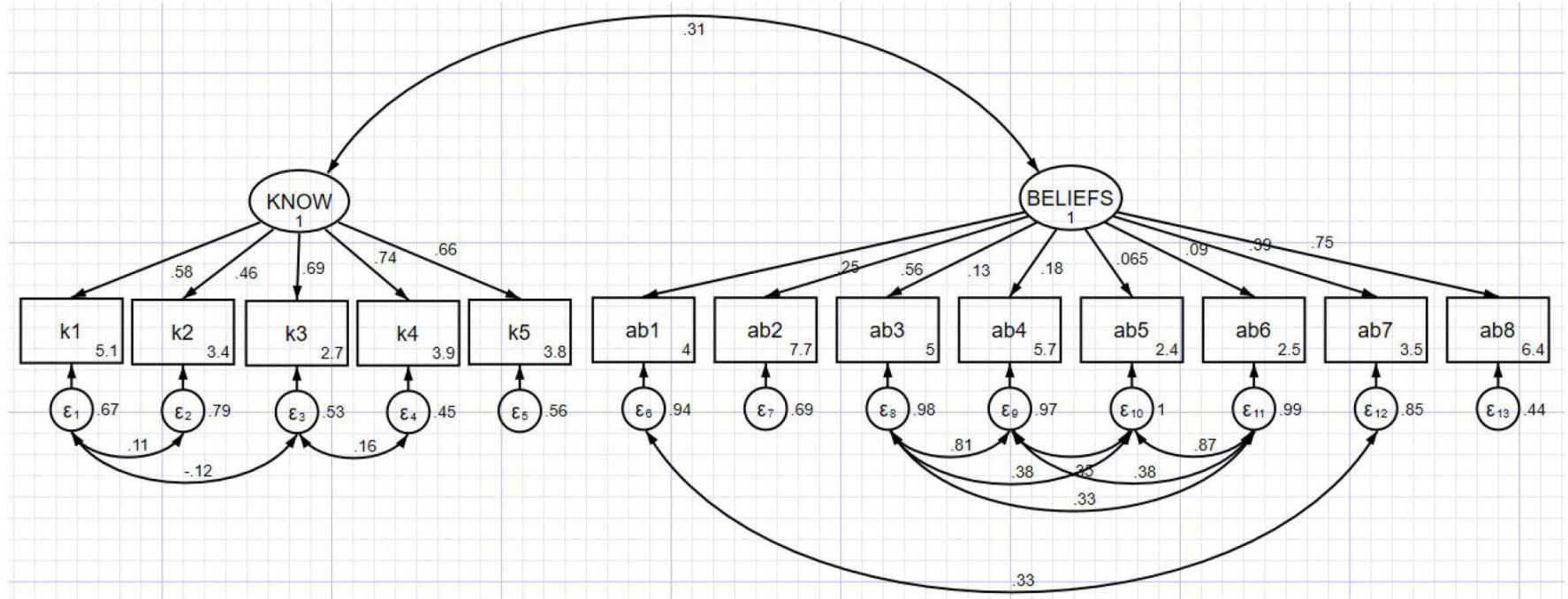

Figure 3 Confirmatory factor analysis, standardised estimates. $\mathrm{N}=611$. Overall $\mathrm{R}^{2}=0.90$. RMSEA=0.40. $\mathrm{CFI}=0.980$. TLI=0.972. $\mathrm{CD}=0.896$. $\mathrm{k} 1-\mathrm{k} 5$ correlate to the five knowledge statements in the survey (see figure 4). $\mathrm{k} 1$ : Every athlete is entitled to equality of opportunity in the pursuit of sport without distinction of any kind and free of discrimination, harassment and violence. k2: Every athlete has the right to freedom of opinion and expression. k3: Every athlete is entitled to have their name, image and performance protected. An athlete's name, image and performance may only be commercially used with their consent, voluntarily given. $\mathrm{k} 4$ : Every athlete has the right to a private life, privacy and protection in relation to the collection, storage and transfer of personal data. k5: Every athlete must be able to access an effective remedy when their rights are not respected and upheld. This is particularly crucial given the highly skilled yet short term and precarious nature of the athletic career. ab1-ab8 correlate to the eight attitude/beliefs statements in the survey (see figure 4). Respondents were asked to agree or disagree, on a 7-point scale to each statement. ab1: It is always ok for me to freely express my opinion. ab2: If someone has access to my personal information, I should know how it is being used. ab3: It is sometimes ok for coaches to use any kind of violence toward me (eg, intimidation, assault, or coercion). ab4: It is sometimes ok for teammates and others to use any kind of violence toward me (eg, intimidation, assault or coercion). ab5: It is sometimes ok for coaches to pressure me in any way. ab6: It is sometimes ok for teammates and others to pressure me in any way. ab7: If I experience behavior that I deem inappropriate, I can seek assistance without fear of consequences or retaliation. ab8: If someone wants to use my personal information, they must always obtain my consent. CFI, Tucker-Lewis Index; RMSEA, root mean square error of approximation; TLI, Tucker-Lewis Index.

such as the world region, sport structure, gender culture of the sport, season of sport or the performance level of athlete). The language used in the WPA declaration was deemed most apt and accessible to most athletes and players. Thus, this wording was used verbatim with minor adjustments in each rights statement to improve inclusion ('his or her' was replaced with 'their' and 'player' was replaced with the universal term 'athlete').

Two different strategies were used to develop the knowledge construct, and the attitudes/beliefs construct. Original language from the WPA declaration was used to test knowledge. Responding to each rights statement, respondents were asked to provide one of three categorical answers: (1) Yes, this statement applies to me; (2) No, this statement does not apply to me and (3) I do not understand this statement.

Scaled statements asking athletes to respond to hypothetical scenarios adapted from each knowledge statement were used to test attitudes/beliefs. Respondents were asked the extent to which they agreed or disagreed with each scenario. A 7-point Likert scale was used as the psychometric response to provide a measure of extremity and direction. ${ }^{21}$ The response scale was coded numerically, from strongly disagree at 1 to strongly agree at 7 , the 'neutral' response was coded to the centre and given a score of $4 .{ }^{22}$

Qualtrics software (Qualtrics, Seattle, Washington, USA) was used to host and deliver the survey. The authors chose to start with the easier cognitive task (ie, yes/no categorical responses, rather than dimensional scale responses) to achieve better engagement and user experience, with a lower likelihood of respondent fatigue and poor completion rate. All seven Likert scale responses were spaced exactly evenly apart, visually, to ensure no response was more or less conspicuous and to discourage the routine selection of any one reply. ${ }^{23}$

The last item allowed a free-text response for any additional feedback, finalising the first draft at five knowledge statements, five attitudes/beliefs statements and open text responses.

\section{Step 2: item development and face validation}

Face validation was used to determine if the instrument would make sense to subject experts and respondents being tested. ${ }^{24-26}$ This step was completed in English. The process was initiated when the authors reviewed the 

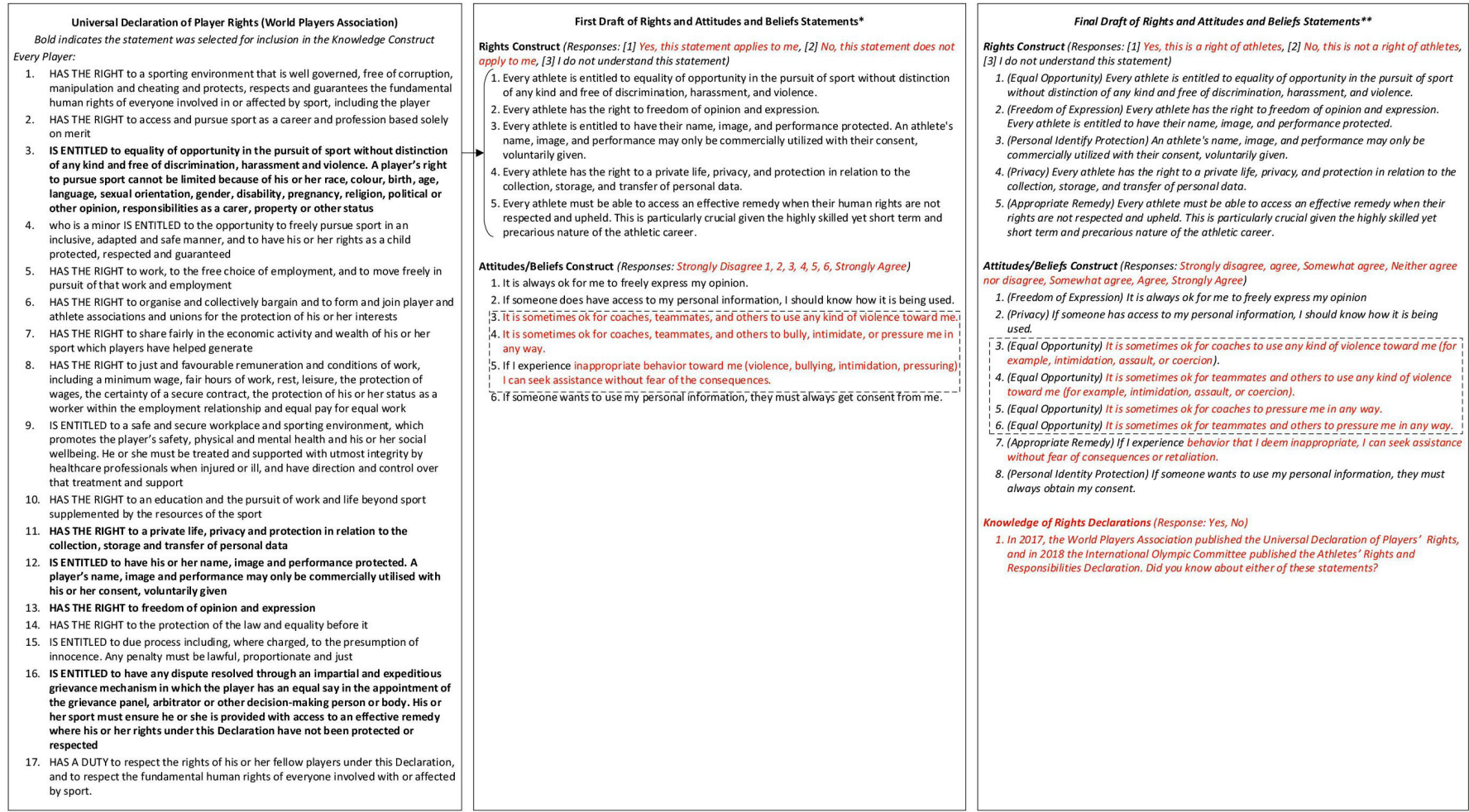

Figure 4 Edits made to survey items following qualitative study (content changes highlighted in red). WPA, root mean square error of approximation.

first draft instrument to determine if the items accurately captured the spectrum of athletes' rights that the vast majority of sport participants should understand and did not contain overt spelling/grammar errors or confusing language. All 13 items were retained.

A usability/understandability test was then conducted by distributing the intact first draft instrument to 10 English-speaking athletes recruited by the authors from diverse sporting and geographical backgrounds. Athletes' participation was voluntary. Respondents' primary sports were track and field, rowing, boxing and soccer. Three competed in Paralympic sport. There was a near equal distribution of men and women. Five countries were represented. Written feedback provided in the free-text box was considered in addition to verbal feedback obtained via semi-structured focus groups designed to explore respondents' interpretation of the broader phenomenon, interpretation of instrument items (question comprehension, interpretation of language, syntax and phrasing), and reactions to the instrument.

Four athletes who completed the survey volunteered to be interviewed. Interviews typically lasted $20 \mathrm{~min}$, were recorded with permission, transcribed verbatim, and anonymised to protect respondents' identities. Interview data were analysed thematically to identify how athletes conceptualised the survey and where there were points of confusion or concern. Concepts such as 'duty holder,' 'duty bearer,' 'athlete image,' 'freedom of expression,' 'violence,' 'redress mechanisms,' 'fair play,' 'remedy and grievance,' 'bullying,' 'pressure' and 'intimidation' were main themes. Interview data were compared with written feedback to assess any new issues that emerged. Testretest repeatability and temporal stability were irrelevant because the goal was to determine, at any given point of time, if athletes know and believe their rights as articulated by global sports authorities-not whether these understandings change over time.

The instrument made several improvements to enhance clarity and end-user experience, described in the results section. As a result, the 13-item Athletes' Rights Survey, comprising five rights and eight attitudes/beliefs statements, was finalised in English and translated into French, Spanish, Russian, Chinese, Japanese and Korean. Two first language speakers reviewed translations. A final multiple-choice question was added, asking athletes if they were aware of the IOC or WPA rights declarations, to understand athletes' knowledge of the declarations of the rights themselves.

\section{Step 3: structural validation and internal consistency testing}

Finally, the full survey was validated between February 2020 and September 2020. A total of 1159 responses were recorded. Cases were excluded if no questions were answered in any section $(n=12)$, no knowledge or attitudes/beliefs questions were answered $(n=410)$, or the participant indicated that they were not an athlete (eg, 'sporting official' or 'part of the sports entourage') $(n=4)$. Responses that recorded 'I do not understand this statement' for each statement in the knowledge construct were also excluded $(n=3)$ because we could not assess these participants' understanding of the survey. Overall, 730 athletes submitted sufficiently complete surveys for 
inclusion in the analysis. The survey was shared broadly on social media, and a response rate of $63 \%$ was calculated based on those who opened the survey compared with those who completed it.

To demonstrate the validity of the survey in testing the athletes' knowledge of rights on the one hand and their attitudes/beliefs on the other, we conducted confirmatory factor analysis using the SEM command in Stata V.16 (StataCorp). A two-factor measurement model was estimated, with the latent factors related to the five knowledge and eight attitudes/beliefs items, respectively. The measurement model depicts the pattern of observed variables for the latent constructs, testing the reliability of the observed variables. ${ }^{27}$ We used maximum likelihood estimation with robust standard errors as the survey data were ordinal and non-normally distributed. ${ }^{28}$ Based on these specifications, 119 observations with missing values across any of the knowledge or attitudes/beliefs statements were further excluded, to a final sample of 611 .

The model tested the level of correlation between the latent factors, represented by the curved path between the latent factors in the theoretical model (figure 3). Based on feedback from step 2, we allowed covariances between the error terms of the equal opportunity (violence/coach) and equal opportunity (pressure/ teammates) (see verbatim statements in figure 4). Ovals and observed factors by rectangles represent latent factors. One-sided arrows indicate the path between latent and observable variables. The statistical significance of path coefficients was established through the Z-values. The root mean square error of approximation (RMSEA), coefficient of determination, Comparative Fit Index (CFI), Tucker-Lewis Index (TLI) are goodnessof-fit indicators for the estimation model. ${ }^{27} 29$ A good fit is indicated by an RMSEA of less than 0.08 and CFI and TLI values larger than 0.90 ). The correlations between observable factors and knowledge statements on the one hand and attitudes/beliefs statements on the other are shown in table 1 .

\section{RESULTS}

\section{Step 1: rapid literature review and item drafting}

In step 1, the literature review yielded no prior instruments testing athletes' understanding of their rights and only two brief, published, publicly available declarations of athletes' rights, introduced above. Thus, categorising rights-related concepts into dimensions of the instrument was straightforward and resulted in a 10-item instrument with items that overlapped only minimally and only when intended by the authors (ie, each knowledge statement had a corresponding attitudes/beliefs statement).

\section{Step 2: item development and face validation}

In step 2, 10 athletes completed the first draft survey. Participants used 4-25 min to complete it, with an average of $12 \mathrm{~min}$. All 10 athletes provided written open-ended

Table 1 Correlations among factors

\begin{tabular}{|c|c|c|c|c|c|c|c|c|}
\hline \multicolumn{9}{|l|}{ Knowledge statements } \\
\hline & & \multicolumn{2}{|c|}{ Equal opportunity } & \multirow[t]{2}{*}{$\begin{array}{l}\text { Freedom of } \\
\text { expression }\end{array}$} & \multirow[t]{2}{*}{$\begin{array}{l}\text { Personal identify } \\
\text { protection }\end{array}$} & \multirow[t]{2}{*}{ Privacy } & \multicolumn{2}{|c|}{ Appropriate remedy } \\
\hline \multicolumn{2}{|l|}{ Equal opportunity } & \multicolumn{2}{|l|}{1} & & & & & \\
\hline \multicolumn{2}{|l|}{ Freedom of expression } & \multicolumn{2}{|l|}{0.34} & \multicolumn{2}{|l|}{1} & & & \\
\hline \multicolumn{2}{|c|}{ Personal identify protection } & \multicolumn{2}{|l|}{0.34} & 0.29 & \multicolumn{2}{|l|}{1} & & \\
\hline Privacy & & 0.44 & & 0.32 & 0.57 & 1 & & \\
\hline Appropriate remedy & & 0.32 & & 0.37 & 0.48 & 0.48 & 1 & \\
\hline \multicolumn{9}{|c|}{ Attitudes and beliefs statements } \\
\hline & $\begin{array}{l}\text { Freedom of } \\
\text { expression }\end{array}$ & Privacy & $\begin{array}{l}\text { Equal } \\
\text { opportunity- } \\
\text { violence/coach }\end{array}$ & $\begin{array}{l}\text { Equal } \\
\text { opportunity- } \\
\text { violence/teammate }\end{array}$ & $\begin{array}{l}\text { Equal } \\
\text { opportunity- } \\
\text { pressure/coach }\end{array}$ & $\begin{array}{l}\text { Equal opportunity- } \\
\text { pressure/teammate }\end{array}$ & $\begin{array}{l}\text { Appropriate } \\
\text { remedy }\end{array}$ & $\begin{array}{l}\text { Personal } \\
\text { identity } \\
\text { protection }\end{array}$ \\
\hline $\begin{array}{l}\text { Freedom of } \\
\text { expression }\end{array}$ & 1 & (17vacy & & & & & & \\
\hline Privacy & 0.1 & \multicolumn{2}{|l|}{1} & & & & & \\
\hline $\begin{array}{l}\text { Equal opportunity- } \\
\text { violence/coach }\end{array}$ & -0.04 & 0.17 & 1 & & & & & \\
\hline $\begin{array}{l}\text { Equal opportunity- } \\
\text { violence/teammate }\end{array}$ & -0.05 & 0.21 & 0.8 & 1 & & & & \\
\hline $\begin{array}{l}\text { Equal opportunity- } \\
\text { pressure/coach }\end{array}$ & -0.07 & 0.06 & 0.38 & 0.37 & 1 & & & \\
\hline $\begin{array}{l}\text { Equal opportunity- } \\
\text { pressure/teammate }\end{array}$ & -0.03 & 0.08 & 0.33 & 0.4 & 0.87 & 1 & & \\
\hline Appropriate remedy & 0.38 & 0.19 & 0.05 & 0.05 & -0.08 & -0.04 & 1 & \\
\hline $\begin{array}{l}\text { Personal identity } \\
\text { protection }\end{array}$ & 0.21 & 0.43 & 0.09 & 0.14 & 0.05 & 0.06 & 0.31 & 1 \\
\hline
\end{tabular}


feedback, and 4 of 10 volunteered to participate in interviews to provide feedback on their experiences of taking the survey. No new issues were identified when comparing athletes' written and verbal feedback.

For the knowledge construct, athletes who were interviewed indicated that the responses to the Rights Construct could be improved by revising to (1) Yes, this is a right of athletes; (2) No, this is not a right of athletes and (3) I do not understand this statement. For the attitudes/ beliefs section, all athletes asked that the word 'violence' be separated from the word 'pressure.' In contrast to the language in the WPA and IOC declarations, where the terms are grouped in the same concept (Every athlete is entitled to equality of opportunity in the pursuit of sport without distinction of any kind and free of discrimination, harassment and violence), athletes felt that the meaning of 'violence' was sufficiently different from the meaning of 'pressure,' 'harassment,' 'harm' and other milder terms that were not unanimously negative and that this difference should be reflected in the structure of the attitudes/beliefs construct. Similarly, most athletes suggested using the word 'pressure' instead of 'harassment' to more accurately reflect their experiences.

Most athletes also asked that statements separate the 'coach' from 'teammates and others.' Athletes noted that 'pressure' and other forces are received and interpreted differently from each group. The athletes further reported that some could consider 'pressure' constructive, motivating and positive when applied tactfully. Some athletes indicated they perform best when their coaches employ it strategically, ethically and respectfully. This may be less acceptable when the 'pressure' comes from a teammate or individual with less authority.

In contrast to the language in the declarations of the original rights, the final Athletes' Rights survey thus separated the word 'violence' from relatively milder forms of abuse and the word 'coach' from 'teammates and others.'
Athletes also reported appreciating the free-text box for feedback and suggested leaving this feature in the final version. Based on athletes' feedback, the final instrument thus contained 13 items and a free-text box. See figure 4 for edits made between the first and final survey drafts.

\section{Step 3: structural validation and internal consistency testing}

A total of 1159 responses were recorded. Cases were excluded if no questions were answered in any section $(n=12)$, no Knowledge or Attitudes/Beliefs questions were answered $(n=410)$, or the participant indicated that they were not an athlete (eg, 'Rugby League referee', 'anything I enjoy and that keeps me fit', 'Physiotherapist' or 'Movement is Medicine') ( $\mathrm{n}=4)$. Responses that recorded 'I do not understand this statement' for all statements in the knowledge construct were also excluded ( $n=3)$ because we were unable to assess these participants' understanding of the survey. As such 730 athletes submitted sufficiently complete surveys for inclusion in the analysis (response rate 63\%). See table 2 for participant demographics.

In step 3, we estimated the theoretical structural equation model, hypothesising that the five human rights statements load onto the latent concept 'KNOW' (knowledge), and the eight attitudes/beliefs items load onto the latent construct 'BELIEFS'. The model had a moderate fit and was further improved by investigating modification indices through the estat mindices command. As such, we estimated 11 factor loadings, 1 factor correlation, 13 error terms and 10 item correlations and variances for each of the two factors (figure 4). With two exceptions (attitudes and beliefs about equal opportunity, which included the word 'pressure'), all path coefficients were statistically significant (see figure 4 for each survey item verbatim). Standardised parameter estimates are provided in figure 4 , and unstandardised estimates are shown in table 3 alongside standardised

\begin{tabular}{|c|c|c|c|c|c|}
\hline Age (years) & $\mathrm{N}(\%)$ & Gender & $\mathrm{N}(\%)$ & Sport category & $\mathrm{N}(\%)$ \\
\hline $18-29$ & $439(60.1)$ & Female & $370(50.7)$ & Olympic & 569 (77.9) \\
\hline $30-41$ & $160(21.9)$ & Male & $360(49.3)$ & Paralympic & $135(18.5)$ \\
\hline$>41$ & $128(17.5)$ & & & & \\
\hline Did not answer & $3(0.5)$ & Did not answer & $0(0)$ & Did not answer & $26(3.6)$ \\
\hline Competition status & $\mathrm{N}(\%)$ & Union membership & $\mathrm{N}(\%)$ & Awareness of declarations & $\mathrm{N}(\%)$ \\
\hline Currently competing & $490(67.1)$ & Yes & $162(22.2)$ & Yes & $124(17.0)$ \\
\hline \multirow[t]{2}{*}{ Retired } & 240 (32.9) & No & $399(54.7)$ & No & $573(78.5)$ \\
\hline & & Do not know & $167(22.9)$ & & \\
\hline Did not answer & $0(0)$ & Did not answer & $2(0.2)$ & Did not answer & $33(4.5)$ \\
\hline Level of competition & & $\mathrm{N}(\%)$ & Sport and $\mathrm{c}$ & & $\mathbf{N}$ \\
\hline International & & 437 (59.9) & Total sport & & 49 \\
\hline National & & $167(22.9)$ & Total coun & & 70 \\
\hline Regional & & $125(17.1)$ & & & \\
\hline Did not answer & & $1(0.1)$ & & & \\
\hline
\end{tabular}


Table 3 Standardisedand unsaturated estimates $(n=611)$

\begin{tabular}{|c|c|c|c|c|c|c|c|c|}
\hline Observable variable & $\begin{array}{l}\text { Latent } \\
\text { construct }\end{array}$ & $\begin{array}{l}\text { Unstandardised } \\
\text { coefficients }\end{array}$ & $\begin{array}{l}\text { Standardised } \\
\text { coefficients }\end{array}$ & SE & $\mathbf{Z}$ & $\mathbf{P}>|\mathbf{z}|$ & $95 \% \mathrm{Cls}$ & $\begin{array}{l}\mathbf{R}^{2} \\
\text { values }\end{array}$ \\
\hline Equal opportunity & KNOW & 1 & 0.58 & 0.03 & 16.27 & 0.000 & 0.49 to 0.61 & 0.30 \\
\hline Freedom of expression & KNOW & 1.1 & 0.56 & 0.04 & 12.25 & 0.000 & 0.39 to 0.53 & 0.21 \\
\hline Personal identity protection & KNOW & 2.0 & 0.69 & 0.03 & 25.91 & 0.000 & 0.65 to 0.76 & 0.50 \\
\hline Privacy & KNOW & 1.6 & 0.74 & 0.02 & 31.68 & 0.000 & 0.73 to 0.83 & 0.62 \\
\hline Appropriate remedy & KNOW & 1.5 & 0.66 & 0.03 & 21.50 & 0.000 & 0.59 to 0.71 & 0.42 \\
\hline Freedom of expression & BELIEFS & 1 & 0.25 & 0.07 & 4.58 & 0.000 & 0.19 to 0.47 & 0.11 \\
\hline Privacy & BELIEFS & 1.4 & 0.56 & 0.09 & 4.64 & 0.000 & 0.24 to 0.58 & 0.17 \\
\hline Equal opportunity - violence/coach & BELIEFS & 0.46 & 0.13 & 0.06 & 2.06 & 0.040 & 0.00 to 0.23 & 0.01 \\
\hline Equal opportunity - violence/teammate & BELIEFS & 0.6 & 0.18 & 0.06 & 2.85 & 0.004 & 0.05 to 0.29 & 0.03 \\
\hline Equal opportunity - pressure/coach & BELIEFS & 0.34 & 0.65 & 0.07 & 0.21 & 0.835 & -0.11 to 0.14 & 0.001 \\
\hline Equal opportunity - pressure/teammate & BELIEFS & 0.48 & 0.09 & 0.06 & 1.03 & 0.304 & -0.06 to 0.18 & 0.003 \\
\hline Appropriate remedy & BELIEFS & 1.8 & 0.39 & 0.08 & 6.18 & 0.000 & 0.33 to 0.64 & 0.24 \\
\hline Personal identity protection & BELIEFS & 2.2 & 0.75 & 0.09 & 6.52 & 0.000 & 0.42 to 0.77 & 0.35 \\
\hline
\end{tabular}

$\mathrm{N}=611$. Overall $\mathrm{R}^{2}=0.90 . \mathrm{RMSEA}=0.40 . \mathrm{CFI}=0.980 . \mathrm{TLI}=0.972 . \mathrm{CD}=0.896$

CFI, Comparative Fit Index; RMSEA, root mean square error of approximation; TLI, Tucker-Lewis Index.

coefficients, Z-values and SEs. The model estimated a weak correlation between the two latent variables $(0.012$ unstandardised, 0.31 standardised), indicating the two constructs-knowledge of rights and beliefs/attitudes about them-are only weakly related. The factor loadings represent the strength of the relationship between an item and a factor. Standardised factor loadings $>0.9$ indicate the factors may be too similar and not contribute enough information to the latent construct. While very low factor loadings may suggest a low contribution to the latent factor, there is no consent on a relative standard of accepted minimum strength. The acceptable strength of the factor loading depends on the theoretically assumed relationship between the item and the factor. ${ }^{28}$ The items with the highest standardised and statistically significant loadings on the beliefs/attitudes construct are the right to personal identity protection $(0.75)$ and the right to privacy of personal information (0.56). Interestingly, while pressure from coaches is among the factors with the highest loading, pressure from teammates and others, is the factor with the lowest loading on the beliefs construct (0.09); both are not statistically significant. The five knowledge factors have similar loadings, between 0.56 and 0.74 , which all contribute almost equally to the knowledge construct. The right to privacy, image protection and ownership, and a remedy for rights violations have the highest loadings $(0.74,0.69$ and 0.66 , respectively).

The goodness of fit indices CFI=0.980, TLI=0.972 and RMSEA $=0.040$ are all within the thresholds, indicating the goodness of fit between the model and the observed data. As such, the SEM results demonstrate the validity of the survey testing athlete's knowledge and beliefs/attitudes.

\section{DISCUSSION}

To the authors' knowledge, this is the first survey instrument designed to understand athletes' knowledge, attitudes and beliefs about publicly available declarations related to their rights in sport. The survey was based on two published declarations of athletes' rights developed by international sports bodies. The instrument was validated with ten international athletes (representatives of the ultimate target group), four of whom participated in feedback interviews. The a priori engagement of athlete experts and the use of verbatim language from the declarations in a short-form instrument increased the efficiency of the development process. In addition, the survey was tested with 1159 athletes and validated through confirmatory factor analysis.

The length and style of the instrument were important considerations. The authors aimed to test a comprehensive range of issues related to athletes' rights in sport settings as described in the WPA and IOC declarations while keeping the overall survey very short, to the point and simple. Further, the instrument primarily involved categorical responses. These design features intended to increase response accuracy and rate and decrease the likelihood of respondent fatigue and task abandonment. Athletes' written and verbal feedback suggests these goals were achieved.

The instrument's language was also important-especially in cases where slight modifications to the exact declaration language were required and when considered by the different perspectives of various sport environments. In contrast to the declarations, athletes' themselves requested a clear delineation between violence and harassment, pressure, intimidation and other terms. Though most respondents thought of violence as unacceptable from either teammates or 
coaches, the combat sports athlete (boxing) felt differently. As violence is embedded in their sport, there was a greater sense of familiarity and acceptance of violence. This insight is consistent with broader discussions of organisational and cultural drivers of abuse in sport. The belief that intentional violence has instrumental effects is called out as a risk factor. ${ }^{16}$ All athletes surveyed, regardless of sport, felt 'violence' is a unique term that should be investigated more deeply. This is important because the words 'violence,' 'harassment' and 'intimidation' are often grouped by administrators and scholars engaged in studying and preventing abuse in sport. In this study, athletes noted they perceive violence, harassment and pressure as very different concepts. Each of them is responded to and interpreted differently when received by coaches, teammates and others.

The quantitative validation had three key findings: First, path coefficients from the attitudes and beliefs about equal opportunity regarding the term 'pressure' were not statistically significant, supporting the qualitative discussion that 'pressure' is a term interpreted differently across cultures and sports. Second, the model estimated only a weak correlation between the two latent variables (0.012 unstandardised, 0.31 standardised), indicating knowing one's rights does not translate directly into believing in and acting on those rights (and potentially vice versa). Third, privacy-related rights, had the highest path coefficients, indicating athletes associated 'rights' more with image and personal data and less with interpersonal treatment per se.

It is unclear whether or not athletes unanimously interpreted the word 'pressure' positively or negatively. During qualitative data collection, it was revealed that 'pressure' is considered by some to be constructive, motivating, and performance-enhancing when strategically used by authority figures such as the coach, but not equal-status actors such as teammates. ${ }^{16}$ Again, this overall call to differentiate between terms and distinguish vertical and lateral relationships has implications for future human rights studies and athlete-facing communications. Special attention should be paid to using language and communication strategies that truly resonate with athletes. The quantitative validation through confirmatory factor analysis demonstrated that the items selected for the survey have a good fit to measure knowledge on the one hand and attitudes and beliefs of athletes concerning their rights on the other. Importantly, it demonstrated that the two constructs of knowledge and attitudes/beliefs, while related, are not strongly correlated. This matters because attitudes/beliefs drive behaviour, and we cannot assume that athletes' and players' rights policies aimed at increasing knowledge will necessarily improve competitors' day-to-day experiences in sport.

The narrow scope of our study is its primary limitation. While study participants represented several countries, sports and (dis)abilities, the cohort had unequal representation for some sports and geographies. However, as the study was based on very brief declarations that represent all competing athletes, this limitation was not considered prohibitive. A second consideration is the instrument's inability to detect how often athletes felt certain behaviours were acceptable in the attitudes/ beliefs section. However, this was not the main focus of the instrument; understanding concordance between athletes' knowledge and their attitudes/beliefs was. Future survey iterations could remove frequency from the attitudes/beliefs statements (ie, sometimes) and include a frequency Likert scale (eg, never to always) as potential responses. This will allow the investigation of athletes' level of acceptance of certain behaviours, that is, how often certain behaviours are acceptable. As such, as the focus here was to understand beliefs rather than level of acceptance, the current scale suffices. Furthermore, while the interview sessions noted some differences in how rights in a sporting context are interpreted based on the sport (eg, violence), we do not believe that our cohort as a whole should be expected to have substantially different understandings of each statement included in this brief survey instrument.

\section{CONCLUSION}

This is the first survey instrument developed to directly test global athletes' knowledge, attitudes and beliefs about their rights in the context of sport, as described by the WPA and IOC. This provides an opportunity to help fill gaps in the growing canon of literature dedicated to sport safeguarding-a human rights concern, and constructively highlight the points of strain between sports environments and athletes' negotiation of their rights within them.

Twitter Yetsa A Tuakli-Wosornu @YetsaTuakli and Margo Mountjoy @\#mmsportdoc Acknowledgements The authors thank the cohort of international athletes who generously participated in this project. Many thanks as well to Dr Veronika Shabanova for guidance during early instrument design and development.

Funding Parts of this work were funded by the Sports Equity Lab in association with the Yale School of Public Health.

Competing interests Two authors (YAT-W and MM), are volunteer members of IOC Prevention of Harassment and Abuse in Sport Working Group. The remaining authors have no competing interests to disclose.

Patient and public involvement Patients and/or the public were involved in the design, or conduct, or reporting, or dissemination plans of this research. Refer to the Methods section for further details.

Patient consent for publication Not applicable.

Ethics approval The study protocol qualified for exempt status after review by the Yale School of Public Health Institutional Review Board, under 45 CFR 46.104(d).

Provenance and peer review Not commissioned; externally peer reviewed.

Data availability statement No data are available.

Open access This is an open access article distributed in accordance with the Creative Commons Attribution Non Commercial (CC BY-NC 4.0) license, which permits others to distribute, remix, adapt, build upon this work non-commercially, and license their derivative works on different terms, provided the original work is properly cited, appropriate credit is given, any changes made indicated, and the use is non-commercial. See: http://creativecommons.org/licenses/by-nc/4.0/.

\section{ORCID iDs}

Yetsa A Tuakli-Wosornu http://orcid.org/0000-0001-5557-6953

Demetri Goutos http://orcid.org/0000-0001-9984-9829 


\section{REFERENCES}

1 Christian Taylor launches new athletics association. athletics Weekly 2019.

2 Mountjoy M, Brackenridge C, Arrington M, et al. International Olympic Committee consensus statement: harassment and abuse (non-accidental violence) in sport. Br J Sports Med 2016;50:1019-29.

3 South Korean sports coach convicted of sexual assault. Available: https://www.bbc.com/news/world-asia-55746565 [Accessed 1 May 2021].

4 Cacciola S, Mather V. Larry nassar sentencing: 'I just signed your death warrant'. The New York Times. 2018/01/24/;Sect. Sports 2018.

5 Wrack S. Fifa examining claims of sexual and physical abuse on Afghanistan women's team. The Guardian. 2018 2018/11/20/.

6 Schwab B. Embedding the human rights of players in world sport. Int Sports Law J 2018;17:214-32.

7 The United Nations General Assembly. The universal declaration of human rights. The United Nations, 1948.

8 Tuakli-Wosornu YA, Sun Q, Gentry M, et al. Non-accidental harms ('abuse') in athletes with impairment ('para athletes'): a state-of-theart review. Br J Sports Med 2020;54:129-38.

9 Vertommen T, Schipper-van Veldhoven N, Wouters K, et al. Interpersonal violence against children in sport in the Netherlands and Belgium. Child Abuse Negl 2016;51:223-36.

10 The International Olympic Committee. The athletes' rights and responsibilities declaration 2018.

11 UNI Global Union. IOC told: "Athlete rights are not a game".

12 Protect, Respect and Remedy: Global Sport and Human Rights. UNI Global Union.

13 Paolo D. Children's rights and sport. Olympic Rev 1998;1998:36-45.

14 Paulo D. Human rights in youth sport: a critical review of children's rights in competitive sport. 1st edn. Routledge, 2004.

15 Rachel D, Prince Zeid Ra'ad AI H. Recommendations for an IOC human rights strategy. Lausanne: international Olympic Committee, 2020/03. Report No 2020.
16 Roberts V, Sojo V, Grant F. Organisational factors and nonaccidental violence in sport: a systematic review. Sport Manag Rev 2020;23:8-27.

17 Tuakli-Wosornu YA, MacLeod JG. Leveraging the adverse childhood experiences (ACEs) framework to strengthen safeguarding in youth sport. Lancet Child Adolesc Health 2021;5:94-6.

18 Hantrais L. Methodological pluralism in international comparative research. Int J Soc Res Methodol 2014;17:133-45.

19 World players association launches Universal Declaration of Player Rights [press release], 2017. Available: uniglobalunion.org

20 The World Players Association. Universal declaration of player rights. 2017 2017/12/14/. Report No.

21 Don AD, Jolene DS, Leah Melani C. Internet, phone, mail, and mixed-mode surveys: the tailored design method. 2nd edn. Toronto, Ontario, Canada: Wiley, 2000.

22 Marjorie AP, Nancy RL, John JS. Making sense of factor analysis: the use of factor analysis for instrument development in health care research. Thousand Oaks, CA: Sage Publications, Inc, 2003.

23 DAd V. Surveys in social research. 5th edn. Crows Nest, Australia: Allen and Unwin, 2002.

24 Beck CT, Gable RK. Ensuring content validity: an illustration of the process. J Nurs Meas 2001;9:201-15.

25 Denise FP, Bernadette PH. Nursing research: principles and methods. Philadelphia, PA: J.B. Lippincott Co, 1995.

26 Sharon SD, Glen EG. Functional assessment and outcome measures for the rehabilitation health professional. Gaithersburg, MD: Aspen Publishers, 1997.

27 Schreiber JB, Nora A, Stage FK, et al. Reporting structural equation modeling and confirmatory factor analysis results: a review. $J$ Educ Res 2006;99:323-38.

28 Knekta E, Runyon C, Eddy S. One size doesn't fit all: using factor analysis to gather validity evidence when using surveys in your research. CBE Life Sci Educ 2019;18

29 Putnick DL, Bornstein MH. Measurement invariance conventions and reporting: the state of the art and future directions for psychological research. Dev Rev 2016;41:71-90. 